\title{
Los bienes temporales de la iglesia: tesoros sagrados para la comunidad cristiana y tesoros culturales para los pueblos
}

\author{
Roque Marcelino Regalado \\ Presbitero, Docente y Párroco de \\ Nuestra Señora Reina de los Mártires, \\ Quezaltepeque, El Salvador.
}

"La visión antropomórfica en las religiones como fundamento de la expresión artística de la fe"

En la mayoría de religiones el hombre siempre ha expresado las realidades trascendentes con una visión antropomórfica ${ }^{1}$. En especial en el judaísmo como en el cristianismo, esta visión ha llevado a atribuir características a Dios que han inspirado la representación plástica del mismo. Así, cuando se describe en los textos sagrados que Dios oye, ve, camina con su pueblo, abraza, golpea, tiene una espada en su mano, etc. Son expresiones de la cercanía de la trascendencia de Dios. Esta expresión plástica con el paso del tiempo en el cristianismo tomó forma en las artes occidentales de tal manera que la cultura plástica de los pueblos se vio revestida de sacralidad. Sin embargo, con la llegada de la cultura moderna, con su producción en masa y la visión de lo desechable, nos ha hecho perder el valor de lo sagrado y de lo cultural. Es necesario recobrar el espíritu de la humanidad y los valores que de la cultura y la fe emanan.

\section{El arte cristiano como medio de ex- presión de la fe y las culturas.}

Para comprender como lo bienes culturales llegaron a ser parte de lo sacro dentro de la vida de la Iglesia, es necesario tener en cuenta algunos hechos históricos que dieron como resultado la unión de lo cultural y la sagrado.

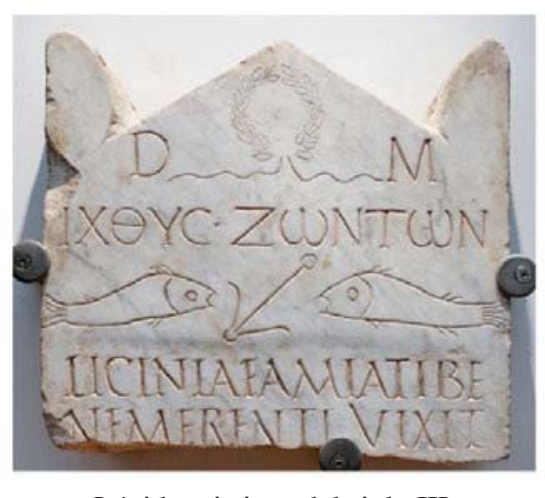

Lápida cristiana del siglo III

1 De acuerdo a la Real Academia de la Lengua Española, antropomorfismo es un conjunto de creencias o de doctrinas que atribuyen a la divinidad la figura o las cualidades del hombre. http://lema.rae.es/drae 


\section{Génesis del arte cristiano}

Con la llegada del cristianismo a las culturas orientales se generó una primera etapa de la producción plástica religiosa de nuestra naciente cultura. Las primeras expresiones artísticas del los cristianos podemos encontrarlas en las catacumbas, ya que en tiempos de persecución las celebraciones de la Eucaristía se celebraban en el interior de estas. Es importante señalar que por la tradición judía tan arraigada enel cristianismo naciente las expresiones plásticas no representaban directamente a Dios ni a Cristo, nada más expresaban simbólicamente su misión. Así podemos encontrar la figura del ICTUS (pescado) que es la colocación de las letras griegas IX $\Theta Y \Sigma$, con sus letras puestas en acróstico, daba la sigla griega de «Jesús Cristo Hijo de Dios Salvador»; la figura del pastor como referente al Yos soy el Buen Pastor; Adán y Eva signos de Cristo y su Iglesia. ${ }^{2}$

Con el edicto de Milán y la llegada la victoria de Constantino sobre Majencio, se declara la libertad religiosa y Constantino como protector del cristianismo. Es aquí donde inicia una nueva etapa de la Iglesia que revolucionó la liturgia y los lugares de celebración. Aunque los obispos cristianos mantenían la postura de prohibir las representaciones plásticas directas de sobre Dios y Cristo, la necesidad de representar y profundizar los dogmas de la fe fue la causa que ayudo a cambiar esta postura. Así podemos encontrar hacia el año 400 d.C. las imágenes de Cristo junto a sus apóstoles. ${ }^{3}$ Ejemplo de esto son la Capilla de san Aquilino en Tesalónica y el Baptisterio de la Basílica de San Lorenzo en Milán. Desde aquí se comienza una historia de cultura y fe dentro de la Iglesia. Más allá de los íconos de las catacumbas, ahora la Iglesia comenzará a construir muchos de los tesoros de valor cultural de la historia de la humanidad.El principal motivo para hacerlo es tratar de construir visiblemente el reino de los cielos en la tierra, se conforma así la edad media y la cristiandad. ${ }^{4}$

\section{La visión de lo sagrado en las obras artísticas.}

En la historia del arte cristiano, es en oriente donde se unen las artes con la espiritualidad. De esta manera el arte se revistió de lo sagrado. Los íconos de Bizancio durante los primeros siglos de la era cristiana fueron elaborados con

2. Plazola, J., Historia del arte cristiano, 12-14.

3. Ibídem 21 .

4. Herrera, H. (1998). Dimensiones de la cultura bizantina. Arte, poder y legado histórico. Santiago: Universidad Gabriela Mistral y Centro de Estudios Griegos, Bizantinos y Neohelénicos Fotios Malleros, Universidad de Chile, 7. Runciman, S. (1988). Bizancio: estilo y civilización. Bilbaio, Xarait, 7. 
un pensamiento de espiritualidad. El arte de occidente trata de representar plásticamente la realidad como la percibe el ser humano, en el arte de oriente religioso el ícono trata de representar la vida interior de la persona o el dinamismo del misterio cristiano que vive. Para la espiritualidad cristiana oriental el ícono es una presencia. Entrar en esa presencia a través del ícono es entrar en comunión con quien está representado en él. La iconografía no es arte religioso decorativo, es ante todo medio de comunicación de las verdades de fe. ${ }^{5}$

Sin embargo, esta práctica espiritual despertó en algunos momentos de la historia de la humanidad discusiones y conflictos como las guerras iconoclastas desatadas en los siglos VIII y IX. A partir del año 730 d.C. comenzó un fuerte movimiento iconoclasta, el primero de dos que azotó la Iglesia, y que culminó en un concilio convocado en Hiereia (cerca de Constantinopla) en el 754 d. C., el cual oficialmente condenó el uso de los íconos. El primer periodo iconoclasta finalizó en el año 787 d.C., con las definiciones y afirmaciones propuestas por el VII Concilio Ecuménico (II Nicea). Sin embargo, entre los años 813 d. C. y 842 d.C., un segundo movimiento iconoclasta remeció la Iglesia, finalizando luego de un Concilio convocado en Constantinopla por la Emperatriz Teodora en el 843 d. C., que ratificó las afirmaciones del II Concilio de Nicea. ${ }^{6}$

El arte sagrado de Occidente empezó a alejarse de esta práctica estética a partir del cisma provocado entre la Iglesia de Roma y La Iglesia de Bizancio en 1054 d.C.Fue con las pinturas de El Giotto (1267-1337) que se inició un estilo de arte religioso, abandonando lo sagrado, marcó así la transición al renacimiento.

\section{Inculturación del evangelio.}

El arte cristiano siempre ha ido tomando elementos de las culturas para lograr la evangelización de los pueblos, y a lo largo de la historia de la humanidad, la Iglesia ha utilizado las imágenes para enseñar. Para los pueblos nativos de América fue diferente, pues el encuentro de las dos culturas fue violento y abusivo, con llevó la destrucción de mucho de la identidad cultural de los conquistados por parte de los conquistadores. En algunas ocasiones se tuvo la

5. Fitzurka, C. Religiosidad Popular y espacio sagrado: El ícono en la teología oriental.Teol. vida [online]. 2003, vol.44, n.2-3 [citado 2013-01-12], pp. 250-264. Disponible en: <http://www.scielo.cl/scielo.php?script=sci_arttext\&pid=S0049-34492003000200010\&lng=es\&nrm=iso $>$. ISSN 0049-3449. doi: $10.4067 /$ S0049-34492003000200010.

6. Ibídem 254. 
certeza de respetar e introducir el cristianismo con la iconografía nativa. "Estos siglos (1521-1790) experimentaron la creación de una tradición colonial híbrida, en el cual elementos europeos y mesoamericanos se mezclaron. En la actualidad, esta tradición colonial es una de las menos estudiadas y apreciadas en la historia del arte."7

En mi opinión este sincretismo se debió al núcleo de la cosmovisión religiosa de los pueblos mesoamericanos, ya que ellos comprendía el cosmos en base a dos clases de densidades: las materias pesadas y las materias ligeras. Así, ordenaban la existencia en dos grandes campos: Lo mundano y lo divino. Lo mundano estaba compuesto por la mezcla de las dos materias, en tal grado que las cosas, animales, plantas, piedras, podían transmitir su materia ligera a los hombres. Los dioses estaban formados de materia ligera imperceptible y poblaban todo el cosmos. ${ }^{8}$

Esta cosmovisión hizo que en el sincretismo religioso de la colonia las imágenes catequéticas que los misioneros utilizaban para representar personajes bíblicos tomaran una visión sagrada ante los nativos. La expresión más grande de este mescla de las cosmovisiones cristiana y mesoamericana es el ícono de la Virgen de Guadalupe. En ella se refleja una imagen de la inmaculada concepción con atuendos mayas. Los colores, los signos, las vestimentas, y su marcado rostro maya lograron calar en la conciencia de estos pueblos.

Los pueblos latinoamericanos tienen una gran visión de lo sagrado, y su veneración por las imágenes es un fundamento clave en la vivencia de la fe. Por tal razón las expresiones plásticas de esas verdades de fe siempre han sido encargadas a grandes maestros, así como la construcción de los templos siempre ha estado ligada al ofrecimiento de lo mejor para la casa de Dios. Esta visión de fe ha ido creando en el patrimonio cultural grandes obras maestras con gran valor artístico y arquitectónico.

\section{Valor cultural de los bienes temporales de la iglesia.}

A lo largo de la historia la Iglesia ha ido desarrollando, entorno a su liturgia y su tradición catequética, innumerables objetos que han sido la expresión

7. Pasztory, E., El arte en Historia Antigua de México, Volumen III:El horizonte postclásico y algunos aspectos intelectuales de la cultura mesoamericana, 465, 2003

8. López Austín, A. La religión, la magia y la cosmovisión. en Historia Antigua de México, Volumen III: El horizonte postclásico y algunos aspectos intelectuales de la cultura mesoamericana, 420-453. 2002. 
cultural y sacra de la visión de fe de los pueblos. Todos estos objetos son tesoros invaluables, no solo por su expresión artística y por su antigüedad, sino también porque muchos de ellos aún son objetos de la más grande devoción de las personas. Medios sagrados que son puertas de fe para entrar en contacto con ese Ser supremo, ese Dios Todopoderoso que humildemente quiere entrar en comunión a la manera humana, a través de nuestros sentidos y de nuestras más bellas expresiones artísticas para despertar los sentimientos más nobles de los corazones de la humanidad.

A estos tesoros que la Iglesia ha custodiado se le denominan bienes temporales según el lenguaje jurídico de la Iglesia. ${ }^{9}$ Estos bienes temporales, también tienen un valor cultural como patrimonio de los pueblos, ya que en ellos se sustenta la identidad y las expresiones propias con las cuales honran lo presencia sagrada. La Iglesia es consciente de este gran tesoro por tal razón dentro de sus organismos institucionales el Papa Juan Pablo II fundó la Pontificia comisión para los bienes culturales de la Iglesia, cuyo papel espresidir la tutela del patrimonio histórico y artístico de toda la Iglesia (obras de arte, documentos históricos, patrimonios libreros y aquellos que se conservan en los museos, bibliotecas y archivos); colaborar en la conservación de este patrimonio con las Iglesias particulares y los respectivos organismos episcopales; promover una sensibilización cada vez mayor en la Iglesia sobre estos bienes, de acuerdo con las Congregaciones para la Educación Católica y para el Culto Divino y la Disciplina de los Sacramentos. ${ }^{10}$ Sin embargo, profundizaremos en este tema en otro apartado.

\section{La cultura de lo desechable y la producción en masa en los objetos sagrados.}

Si bien la tecnología ha ayudado en gran manera a hacer del arte algo universal, de tal manera que se es capaz de reproducir imágenes y esculturas con gran fidelidad y en grandes cantidades. Sin embargo, esto ha cambiado el valor de las obras artísticas reproducidas. Es muy común encontrar hoy en día reproducciones de toda clase de obras artísticas en toallas, calendarios, calcomanías, portadas de libros de notas, etc. Desde la más fiel hasta aquellas que por la intuición iconográfica uno puede adivinar que se trata de una Última Cena de Leonardo, o de una Virgen de Guadalupe con colores invertidos.

9 Código de derecho canónico, Libro V Cánones 1254 - 1268.

10 Para una mayor referencia consultar http://www.vatican.va/roman_curia/pontifical_commissions/ pcchc/documents/rc_com_pcchc_pro_20051996_sp.html 
El postmodernismo, el marketing y los medios de comunicación han ido fraguando una cultura de lo desechable donde los parámetros de lo estético, lo moral y lo sagrado ha ido desvaneciéndose, prevaleciendo así diferentes conceptos sobre arte, cultura, moral y religión. Algunos factores que han transformando nuestra civilización son el espectáculo, la moda y la cultura en masa. ${ }^{11}$

No podemos negar que una de las grandes virtudes de esta civilización ha sido la universalización de la cultura. Todos podemos acezar al conocimiento, al arte, la música, etc. Pero aun alto precio: asimilación superficial. Esto responde al gran valor que se le da al consumo. ${ }^{12}$ Todos estos cambios de paradigmas culturales también ha cambiado la percepción de los patrimonios culturales en los diferentes estratos de la sociedad. Aún dentro de la misma visión cristiana se han vulnerado muchos paradigmas que no permiten descubrir ni el valor cultural, ni el valor sagrado de muchas Iglesias, ornamentos, copones, cálices, etc. Especialmente el consumismo ha provocado que muchos de los materiales con que se elaboran estos utensilios sagrados sean de materiales desechables, para poder fabricarlos en masa. ¿Qué consecuencias trae estos cambios? Dejamos de elaborar patrimonio y desvaloramos el que ya existe.

\section{La cultura de lo desechable y la pérdida de la visión de lo sagrado en los objetos litúrgicos.}

En medio de esta cultura de lo desechable se constata la influencia del consumo y marketing en la elaboración de objetos sagrados y construcciones de templos. Muchos de las nuevas adaptaciones litúrgicas cometen el error de la practicidad. La elaboración de objetos sagrados con materiales desechables y la construcción de templos sin mayor simbología cristiana e identidad cultural de los pueblos, hace que la creación del patrimonio disminuya y más aún desaparezca. Esta misma influencia hace que en la liturgia se invierta menos en la restauración y se consuman objetos de producción en masa por su economía. Así, también se pierde la visión de lo sagrado, ya que aquellos objetos que se utilizaban para el culto terminan abandonados en un desván, en cajas y en el peor de los casos vendidos. Guardados en lugares que no reúnen las condiciones necesarias para la preservación de la plata, el oro o el bronce, terminan por derruirse.

\footnotetext{
11 Vargas Llosa, M., La civilización del espectáculo, 33-64.

12 Vera-Pinto, I., Cultura Desechable. Tomado de http://www.edicioncero.cl/29/07/2012/culturadesechable.html , citado el 6/02/2013.
} 
El poco conocimiento del clero sobre el tema de valores culturales y la poca espiritualidad que valore lo sagrado de los objetos litúrgicos, porque en este campo no podemos asumir ignorancia, hace al final un bajo perfil en la valoración de los tesoros sagrados y culturales que se poseen en la Iglesia. Las normativas que el concilio Vaticano II presenta al respecto son muy claras. Los Obispos son los primeros en velar que los objetos sagrados de alto valor artístico no sean vendidos ni dispersados. ${ }^{13}$

\section{La cultura de la producción en masa y la pérdida del valor cultural en la iglesia.}

La producción en masas de la iconografía cristiana y de objetos sagrados es un cambio cultural dentro de la misma Iglesia, ya que muchos de estos objetos litúrgicos no tienen un valor de unicidad y expresión artística que con el paso del tiempo pueda convertirlo en un objeto de valor cultural. Muchas de las tradiciones que generaban patrimonio cultural han sido borradas y casi extintas en nuestra era de producción en masa. Para el caso la imaginería en tallado de madera, policromados, pintoras en óleo de los misterios de la fe, fabricación de vitrales montados en estructura de estaño, elaboración de cálices en oro, plata y con expresión artística única. Todas estas fuentes de objetos culturales y sagrados has sido cambiados por las imágenes de impresiones foto técnicas y computarizadas.

Por ejemplo para una comunidad cristiana o una cofradía es difícil encontrar personas que fabriquen imágenes con verdadero arte religioso tradicional. Podemos encontrar imágenes de todo tipo fabricadas por centenares en máquinas que tiene como materia base la resina de vidrio, con un perfil iconográfico que muchas veces raya en el sentimentalismo y no en una iconografía que inspire a los fieles contemplar el misterio representado. ¿Podrá una de estas imágenes producida en masa alcanzar un valor cultural con el paso de los tiempos? ¿Cálices o copones de madera fabricados en cientos, podrán adquirir un valor cultural?

\section{La visión sagrada y cultural de los bienes temporales de la Iglesia.}

Es importante recuperar estos dos ejes valorativos en los bienes temporales de la Iglesia. Por esta razón es importante que conozcamos la importancia que la Iglesia da, al menos en los documentos magisteriales, a todo ello.

13 Concilio Vaticano II, Constitución sacrosacntumconcilium, 126b. 
Ya en la ley especial de protección al patrimonio cultural el Estado reconoce el valor cultural de los objetos sagrados, que lo han adquirido por su antigüedad y su historia. En el artículo 3, literal "l", reconoce como patrimonio cultural La imaginería, retablos, parafernalía o utilería religiosa de valor histórico.

Existe la legislación eclesiástica y la reflexión pastoral en torno a la administración de los bienes culturales y sagrados que la Iglesia posee. Me permito sacar a luz algunos de ellos y citarlos literalmente en sus partes más importantes:

\section{Lo que los documentos de la Iglesia aportan en el cuidado de los bienes sagrados y de valor cultural.}

Empezamos por un documento importante como es la carta de la Comisión Pontificia para el Patrimonio Cultural de la Iglesia, con el cual urge a todos los administradores de patrimonios culturales eclesiásticos a conservarlos y protegerlos.

El impacto del patrimonio histórico-artístico de la Iglesia en su conjunto del patrimonio cultural de la humanidad es enorme, tanto por la cantidad y variedad de productos, tanto por la calidad y la belleza de muchos de ellos. Ni siquiera se puede hablar de las personalidades eminentes que han puesto su talento al servicio de la Iglesia. Toda vocación artística, de hecho, dan testimonio de que el mensaje cristiano a todos los pueblos. Todas las obras de arte inspiradas en los valores cristianos son una expresión de la espiritualidad universal y local. Se puede coincidir con la búsqueda religiosa individuo y la comunidad, llegando, en algunos casos, las formas de armonía total entre el fruto creativo y espiritual.

La función de ininterrumpida cultural y eclesial que produce esos bienes es el mejor apoyo para su conservación. Piensa en lo difícil y costoso que la comunidad se convierte en el mantenimiento de las estructuras que han perdido su propósito original y la complejidad de las decisiones para identificar nuevas. Además de la "protección de la vida" del patrimonio cultural es importante, por tanto su "contexto de conservación”, ya que el desarrollo debe entenderse como un todo, especialmente en lo que respecta a los edificios sagrados, donde existe la mayor parte del patrimonio histórico-artístico de la Iglesia. ${ }^{14}$ 14. Comisión Pontificia Para El Patrimonio Cultural De La Iglesia, carta a las necesidades y la urgencia de inventario catalogación y el patrimonio cultural de la iglesia, ciudad del vaticano, 08 de diciembre 1999. Tomado de http://www.vatican.va/roman_curia/pontifical_commissions/pcchc/documents/ rc_com_pcchc_19991208_catalogazione-beni-culturali_it.html

REVISTA DE MUSEOLOGÍA KÓOT, 2013, AÑO 3, No 4, ISSN 2078-0664, ISSNE 2307-3942 
El Código de Derecho canónico sobre la administración y el cuidado de los bienes temporales dice lo siguiente:

\section{4}

$\S 1$. Todos los administradores están obligados a cumplir su función con la diligencia de un buen padre de familia.

\section{§. Deben por tanto:}

1 vigilar para que los bienes encomendados a su cuidado no perezcan en modo alguno ni sufran daño, suscribiendo a tal fin, si fuese necesario, contratos de seguro;

2 cuidar de que la propiedad de los bienes eclesiásticos se asegure por los modos civilmente válidos;

3 observar las normas canónicas y civiles, las impuestas por el fundador o donante o por la legítima autoridad, y cuidar sobre todo de que no sobrevenga daño para la Iglesia por inobservancia de las leyes civiles, ${ }^{.15}$

Nótese que los administradores deberán buscar asegurar los bienes con contratos de seguros y por modos civilmente válidos. Esto implica apoyarse en las legítimas autoridades de las normas civiles para lograr una mayor protección de los bienes, en especial de los patrimonios culturales.

El concilio Vaticano II también urge en conformar comisiones de peritos y clérigos encargados de la música y el arte sacro, para una acción pastoral organizada que permita la orientación de los artistas en la creación con contenido teológico y una mejor vivencia de la liturgia en la Iglesia.

46. Además de la Comisión de Sagrada Liturgia se establecerán también en cada diócesis, dentro de lo posible, comisiones de música y de arte sacro. Es necesario que estas tres comisiones trabajen en estrecha colaboración, y aun muchas veces convendrá que se fundan en una sola.

Estás comisiones también velarán por el cuidado del patrimonio cultural, como principal responsable el ordinario del lugar, es decir el Obispo.

126. Al juzgar las obras de arte, los ordinarios de lugar consulten a la Comisión Diocesana de Arte Sagrado, y si el caso lo requiere, a otras personas muy

15. Código de Derecho Canónico, Título II De la administración de los bienes (Cann. 1273 - 1289). 
entendidas, como también a las Comisiones de que se habla en los artículos 44,45 y 46.

Vigilen con cuidado los ordinarios para que los objetos sagrados y obras preciosas, dado que son ornato de la casa de Dios, no se vendan ni se dispersen.

También ordena la formación artística del clero para que posea criterios claros en su valoración del patrimonio.

129. Los clérigos, mientras estudian filosofía y teología, deben ser instruidos también sobre la historia y evolución del arte sacro y sobre los sanos principios en que deben fundarse sus obras, de modo que sepan apreciar y conservar los venerables monumentos de la Iglesia y puedan orientar a los artistas en la ejecución de sus obras.

3.2. Aportes para la buena administración de los bienes sagrados y culturales. Después de exponer algunos puntos importantes sobre la situación de los bienes culturales y sagrados en la Iglesia quisiera dar algunos aportes en este campo:

a. Es necesario que la Iglesia y el estado a través de sus ministerios hagan un buen acuerdo para el cuidado del patrimonio cultura, ya que en nuestro país es de todos sabido que muchos inescrupulosos asaltan las Iglesias para vender en el mercado negro el poco patrimonio que nos queda. Es importante y urge como lo dice la pontificia comisión para el Patrimonio Cultural, y en este campo se necesita la ayuda de personas expertas. Algunas parroquias han tenido malas experiencias en años anteriores con las autoridades del Estado encargadas del patrimonio cultural, Basta citar los casos de templos que para el 2001 quedaron casi destruidos o inhabitables tales como: El Carme en Santa Tecla y Santiago Apóstol en Tenancingo. Sin embargo, las comunidades parroquiales no pueden construir algo nuevo porque las autoridades no les permiten, y no pueden repararlo porque tampoco se permite, a tenor de lo que la ley especial de protección del patrimonio dice en el art. 41: Asimismo, se suspenderá toda obra iniciada y no podrá continuarse sino con la autorización del Ministerio y bajo la supervisión de delegados de éste. Sin embargo, la segunda parte de este artículo no se ha cumplido, aun se siguen esperando a los delegados del Ministerio. No se agilizan trámites o no se dan soluciones concretas. Mientras tanto los fieles siguen celebrando en templos provisionales. Hay que recordar que no solo son bienes culturales, ante todo son templos para el culto de los fieles a Dios y los fieles tienen el derecho 
de utilizarlos como tales. Urge que se haga el esfuerzo por avanzar en este campo.

b. Tanto autoridades eclesiásticas como civiles deben de reconocer que solo son administradores porque los bienes temporales de la Iglesia pertenecen al pueblo católico. Por tanto no deben tomarse decisiones arbitrarias sobre los patrimonios culturales de la Iglesia sin la previa consulta de los fieles y sin asesorarse de especialistas en el campo .

c. Es necesario iniciar una adecuada educación sobre el patrimonio cultural, en la valoración de las artes, y en historia de nuestro pueblo, tanto en los fieles como en el clero. Esto ayudaría a que en el país se valorara mejor nuestra identidad cultural y lo que de ella aún existe en edificios, templos, imágenes, etc.

d. Es bueno que los párrocos de parroquias que tiene años de fundación, animado por el concilio Vaticano II, se interesen en la catalogación y el cuidado de los bienes sagrados y culturales. Esto implica tener alto grado de responsabilidad con el legado que los mismos fieles, sacerdotes y obispos han depositado en manos de la Iglesia por siglos y que ahora son piezas históricas y valiosas.

e. Es importante que la Iglesia y el Estado colaboren en proteger el patrimonio cultural religioso y evitar que siga impune el tráfico de ilícito de estos . Es necesario tomar conciencia que estos bienes que son tazados como objetos culturales, tiene un gran valor sagrado para la fe de los fieles y deben de cumplir su objetivo para el cual fueron hechos, que es la veneración de los fieles y no terminar en la vitrina de coleccionistas privados.

\section{Conclusión.}

Mucho de lo que ha sucedido en nuestro patrimonio cultural religioso se debe al gran descuido que la Iglesia y el Estado han tenido. La falta de educación de los fieles además de la cultura post moderna de lo desechable y la producción en masa, todos estos son factores que son posibles superarlos en la medida que la Iglesia y el Estado tomen conciencia que tienen el deber moral ante los fieles de administrar con mucha diligencia estos tesoros que son testimonio de la historia cultural, artística y religiosa de nuestro pueblo. 
Estos grandes tesoros deben ser resguardados para que sigan cumpliendo su finalidad de ser obras de arte que animan a la visión de la fe. Es necesario que la visión científica antropológica siempre tenga el respeto de lo que estos objetos representan para la visión de fe de los fieles. Es necesario que la visión religiosa de los fieles respete el valor cultural que mana de los objetos sagrados y que la visión científica antropológica les da con sus estudios.

A la base del problema se encuentran las diferencias de visiones, los temores y las desconfianzas; sin embargo, estas dos visiones religiosa y cultural, no son contrarias sino complementarias pues todo hombre es humano y a la vez divino. Es cultura y religación. Y esto va tejiendo la historia de los pueblos. Debemos reconciliar estas dos visiones para salvar lo poco que nos queda de estos tesoros sagrados para la comunidad cristiana y tesoros culturales para los pueblos.

\section{Referencias bibliográficas}

Plazaola, J., Historia del arte cristiano, BAC, España 1999.

Herrrera, H., Dimensiones de la cultura bizantina. Arte, poder y legado histórico. Santiago: Universidad Gabriela Mistral y Centro de Estudios Griegos, Bizantinos y Neohelénicos Fotios Malleros, Universidad de Chile, 1998.

Fitzurka, C., Religiosidad Popular y espacio sagrado: El ícono en la teología oriental. Teol. vida [online]. Vol.44, tomado de www.teologiayvida.org. 2003.

Pasztory, E., El arte en Historia Antigua de México, Volumen III: El horizonte postclásico y algunos aspectos intelectuales de la cultura mesoamericana. 2003.

López, A. La religión, la magia, y la cosmovisión, en Historia Antigua de México, Volumen III: El horizonte postclásico y algunos aspectos intelectuales de la cultura mesoamericana. 2002.

Conferencia Episcopal De España, Código de derecho canónico, EDICEPC.B., España 1993.

Vargas Llosa,M.,La civilización del espectáculo, Santillana Ediciones Generales, México 2012.

Vera-Pinto, I., Cultura Desechable. http://www.edicioncero.cl/29/07/2012/cultura-desechable.html . 2012. 
Concilio Vaticano II, Constitución sacrosacntum concilium, BAC, España 1991.

Comisión Pontificia Para El Patrimonio Cultural De La Iglesia, carta a las necesidades y la urgencia de inventario catalogación y el patrimonio cultural de la iglesia, ciudad del vaticano, 08 de diciembre 1999.

García, T., Dimensión social de tráfico ilícito de bienes culturales, en kóot Revista de museología, año 2 Octubre 2012, № 3, Museo Universitario de Antropología, Universidad Tecnológica de El Salvador, Tecnoimpresos, SA de CV, El Salvador 2012.

Ley Especial De Proteccion Al Patrimonio Cultural De El Salvador, Decreto Legislativo No: 513, D. Oficial: 98 Tomo: 319, Publicado el 05/26/1993. 1993.

Manzanilla, Linda; López Luján, Leonardo Historia antigua México, vol. III, El horizonte posclásico y algunos aspectos intelectuales de las culturas mesoamericanas, México, INAH, 1995. 


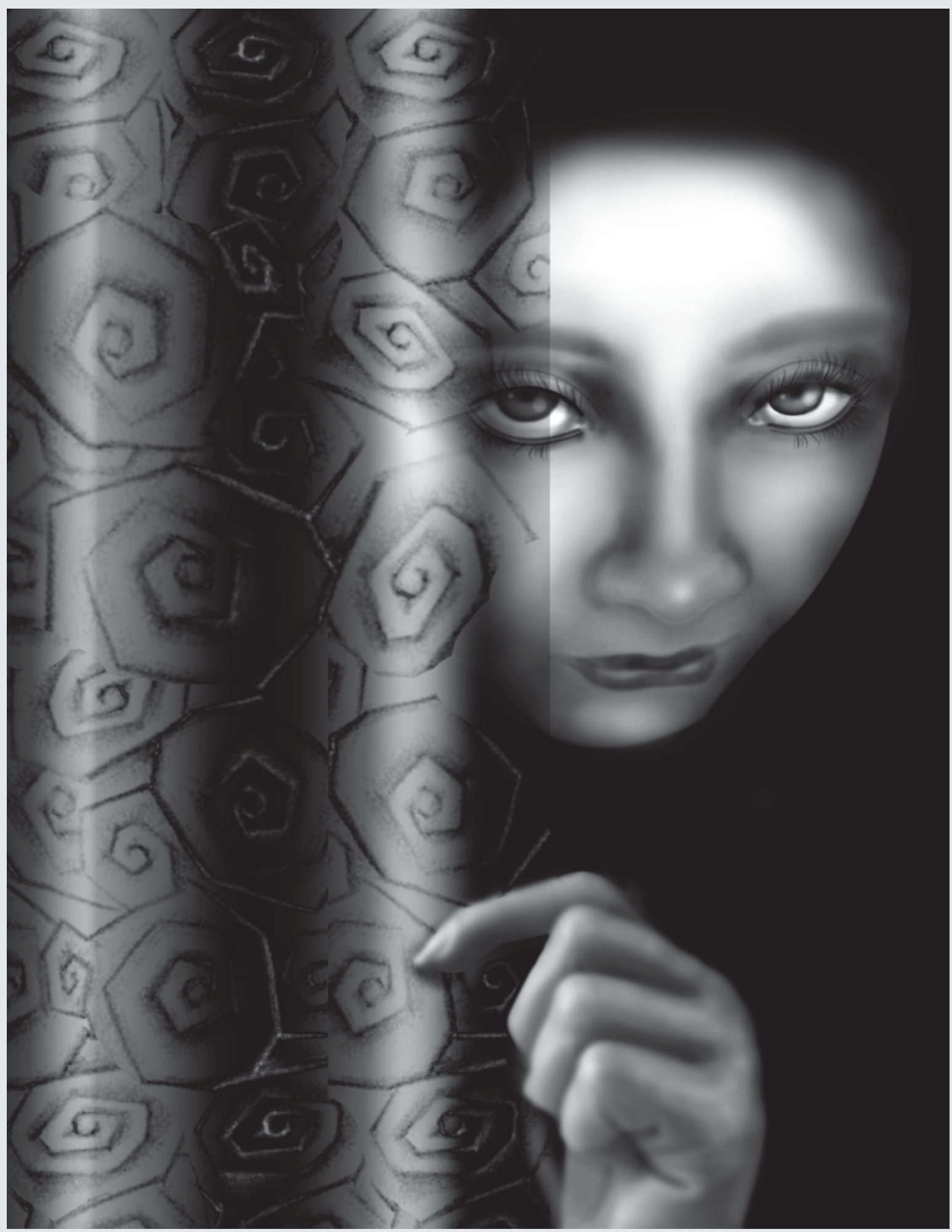

Timidez. Técnica mixta, 8.5” x 11". Rita Araujo. 2013. 